Research Article

\title{
Evaluation of a Cold-Mixed High-Performance Polyurethane Mixture
}

\author{
Sun Min, ${ }^{1,2}$ Yufeng Bi, ${ }^{3}$ Mulian Zheng $\mathbb{D}^{1},{ }^{1}$ Sai Chen, ${ }^{3}$ and Jingjing $\mathrm{Li}^{4}$ \\ ${ }^{1}$ Key Laboratory for Special Area Highway Engineering of Ministry of Education, Chang'an University, Xi'an, \\ Shaanxi 710064, China \\ ${ }^{2}$ Shandong Jianzhu University, Jinan, Shandong 250101, China \\ ${ }^{3}$ Shandong Provincial Communications Planning and Design Institute, Jinan 250031, Shandong, China \\ ${ }^{4}$ School of Highway and Railway Engineering, Shaanxi College of Communication Technology, Xi'an, Shaanxi 710018, China
}

Correspondence should be addressed to Mulian Zheng; zhengml@chd.edu.cn

Received 9 June 2019; Revised 22 September 2019; Accepted 3 October 2019; Published 7 November 2019

Academic Editor: Frederic Dumur

Copyright (C) 2019 Sun Min et al. This is an open access article distributed under the Creative Commons Attribution License, which permits unrestricted use, distribution, and reproduction in any medium, provided the original work is properly cited.

\begin{abstract}
The energy consumption and greenhouse gas emission of asphalt pavement have become a very serious global problem. The hightemperature stability and durability of polyurethane (PU) are very good. It is studied as an alternative binder for asphalt recently. However, the strength-forming mechanism and the mixture structure of the PU mixture are different from the asphalt mixture. This work explored the design and performance evaluation of the PU mixture. The PU content of mixtures was determined by the creep slope $(K)$, tensile strength ratios (TSR), immersion Cantabro loss (ICL), and the volume of air voids (VV) to ensure better water stability. The high- and low-temperature stability, water stability, dynamic mechanical property, and sustainability of the PU mixture were evaluated and compared with those of the stone matrix asphalt mixture (SMA). The test results showed that the dynamic stability and bending strain of the PU mixture were about 7.5 and 2.3 times of SMA. The adhesion level of PU and the basalt aggregate was one level greater than the limestone, and basalt aggregates were proposed to use in the PU mixture to improve water stability. Although the initial TSR and ICL of PU mixture were lower, the long-term values were higher; the PUM had better long-term water damage resistance. The dynamic modulus and phase angles $(\varphi)$ of the PU mixture were much higher. The energy consumption and $\mathrm{CO}_{2}$ emission of the PU mixture were lower than those of SMA. Therefore, the cold-mixed PU mixture is a sustainable material with excellent performance and can be used as a substitute for asphalt mixture.
\end{abstract}

\section{Introduction}

Climate change and global energy shortages are the main obstacles to international sustainable development [1]. Therefore, emission reduction and energy-saving materials have gained more and more attention all over the international community $[2,3]$. Asphalt pavements are widely used due to their low cost, and about $90 \%$ of the world's pavements adopt hot-mix asphalt mixture (HMA) [4]. However, the production of HMA require a large amount of energy and release $\mathrm{CO}_{2}$ and volatile organic compounds (VOCs) and smoke to the air $[5,6]$, which are hazardous to the environment and workers [7].

With the emphasis on energy saving, emission reduction, low carbon, and environmental protection, more and more studies focus on cold-mixed mixtures. At present, the mostly used cold mixture is emulsified asphalt mixture and liquid asphalt mixture. The emulsified asphalt and liquid asphalt are used as binders, which are mixed with aggregates to produce mixtures at room temperature. However, the performance of these mixtures is lower than that of conventional HMA $[5,8]$. Therefore, a new cold mix pavement material needs to be developed urgently [9]. For these reasons, many researchers are looking for more sustainable materials. Polyurethane (PU) is a synthetic material with a wide range of applications [10]. It is mainly prepared from isocyanate and various hydrogen donor compounds. The raw material of PU can be obtained from vegetable oils [10]. And, PU has excellent heat resistance and mechanical properties [10]. Polyurethane mixtures can be prepared at room temperature without heating aggregates and binders [11]. Several researchers investigate the properties of PU 
mixtures and propose their use in pavement structures [11-17]. The structure of the PU mixture is various. The porous PU mixture (PPM) is often studied, which is composed of PU and single-size aggregates.

The deformation resistance, slip resistance, fatigue resistance, and corrosion resistance of PPM were evaluated by Wang et al. [12]. The properties of PPM are greater than those of asphalt mixtures, but the water stability is poor [12]. Cong et al. proposed to use PPM to substitute the opengraded friction course (OGFC) surface layer [13]. The PPM has three times higher stability, which is over one order of magnitude greater than OGFC [13]. The durability and functional performance of PPM and OGFC are studied and compared by Chen et al. [14]. The PPM has much better high permeability, a lower raveling potential, and greater acoustic absorption than OGFC. The increase of PU content can enhance the raveling resistance of PPM [14]. The ice-mixture composite specimens are prepared using asphalt binders and $\mathrm{PU}$ with the traditional asphalt concrete gradation by Chen et al. [14]. It is proposed using the PU mixture on roadways in cold regions to provide better anti-icing and deicing performance as well as enhance traffic safety in the winter seasons [14]. Sun used PU and rubber particles in the asphalt mixture to eliminate snow via self-stress and obtained a good high- and low-temperature performance [15]. A one-component moisture curing $\mathrm{PU}$ is used as the binder in the poroelastic mixture (PERS) [16]. Chen et al. [17] studied the interface shear performance between PPM and the asphalt mixture sublayer. The interface shear strength under different working conditions is analyzed. Wang et al. explored the suitability of PERS with the PU binder for urban roads in cold regions. Both laboratory tests and numerical simulations are conducted to characterize the mechanical and functional performances of PERS using conventional porous asphalt (PA) as reference [18]. Wang et al. investigated the effects of various composition factors on the rutting resistance of PERS so as to provide recommendations on appropriate PERS composition [19]. Lu et al. [20] characterized the primary mechanical behavior of polyurethanebound pervious mixtures by using modified testing methods and combining standards of concrete and asphalt. The hydraulic properties of PU mixture materials are evaluated by considering unsaturated flow [21]. A new sustainable pervious pavement material is prepared using the recycled ceramic aggregate and bio-based PU binder [22].

The recent studies mainly focused on PPM, PERS, or PU concrete as potential substitutes for asphalt mixtures [1122]. However, the water stability of these mixtures was poor, and the PU content was high, which limited the popularity of PU mixtures. In order to solve this, the aggregate interlocking theory in the GB5 mixture design method was used for the gradation design of the PU mixture, and the optimum PU dosage was selected according to the water stability indexes. The stone matrix asphalt mixture (SMA) was the most used material in the upper layer of high-grade highways in China, so the performance of the PU mixture with the interlocking structure (PUM) was evaluated and systemically compared with SMA. The high- and low-temperature stabilities, the dynamic mechanical properties, and the water stability were evaluated. Four improved water stability evaluation tests were recommended to assess the water stability of mixtures. The dynamic mechanical properties of the mixtures with different temperatures and load frequencies were compared. The emissions and energy consumption of PUM and SMA were also calculated and compared. The results provided a technical reference for the application of PUM.

\section{Materials and Methods}

\subsection{Raw Materials}

2.1.1. Polyurethane. The PU binder was a black liquid, as shown in Figure 1. It was a single-component wet curing material, which was synthesized from isocyanate and polyester polyol [23]. The technical properties of PU are shown in Table 1. The PU binder was sealed at room temperature.

2.1.2. Aggregates. Because the PU binder is very sensitive to water, the aggregates need to be dehumidified and cleaned. The operation time of the PU binder is short, so the fieldmixing method is proposed to produce the mixture, and the kinds of the aggregates cannot be too many to ensure the field-mixing quantity. The PUM was designed with two kinds of aggregates, which were obtained from the hot material warehouse of the asphalt mixture mixing station. The coarse aggregate was basalt $(5-10 \mathrm{~mm})$, and the fine aggregate was limestone $(0-3 \mathrm{~mm})$, as shown in Figure 2 . Both aggregates were produced by Liming Heavy Industry, Yantai, China.

\subsection{Polyurethane Mixture Design}

2.2.1. Aggregate Gradation Design. The aggregate gradation of PUM was determined based on the aggregate interlocking theory of the GB5 mixture design method, which was proposed by Olard et al. [24, 25]. The interlocking theory and the design steps were described in the previous study [26]. As far as aggregate interlocking theory is concerned, the parameter $p_{t}$ is defined as the proportion of the coarse aggregate for which there is no interference between two adjacent aggregates, and the mineral density reaches maximum. The parameter is then used to eliminate the influence of boundary and discrete interaction on the void ratio of aggregates.

The optimum design process of the two aggregates is shown in Figure 3. The $p_{t}$ was equal to $75 \%$; therefore, the proportion of the two aggregates $(5-10 \mathrm{~mm}$ and $0-3 \mathrm{~mm})$ is determined to be $75: 25$.

And, the PUM and SMA with a maximum nominal particle size of 10 and $13 \mathrm{~mm}$ were prepared and evaluated. The SMA was designed according to the Marshall mix design method. The fiber content of SMA was $0.3 \%$. The styrenebutadiene-styrene- (SBS-) modified asphalt content of SMA was $5.8 \%$. The mineral aggregate gradation of PUM and SMA is presented in Figure 4. 


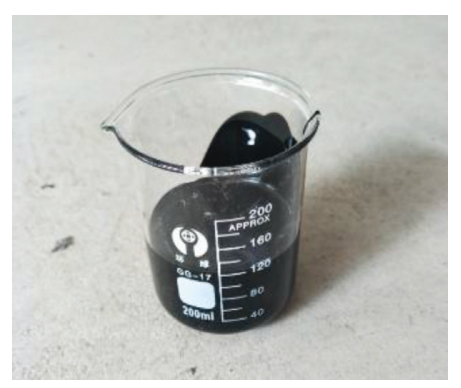

FIgURe 1: PU binder.

TABle 1: Basic properties of the PU binder.

\begin{tabular}{lc}
\hline Projects & Value \\
\hline Density $\left(\mathrm{g} / \mathrm{cm}^{3}\right)$ & 1.17 \\
First curing time $(\mathrm{min})$ & $25 \sim 60$ \\
Last curing time $(\mathrm{min})$ & $1500 \sim 2000$ \\
Tensile strength $(\mathrm{MPa})$ & 6.7 \\
Elongation ratio $(\%)$ & 350 \\
\hline
\end{tabular}

2.2.2. Polyurethane Content Determination. Water stability and interlayer bonding properties are two key factors that limit the large-scale application of PU mixtures [13, 14, 17]. Because of this, the PU content was determined based on water stability to avoid water damage. The freeze-thaw splitting test, Cantabro loss test, and Hamburg wheel tracking tests (HWTD) were performed to evaluate the water stability [10]. Thus, the creep slope value $(K)$, the freeze-thaw tensile strength ratio (TSR), the Cantabro loss (ICL), and the volume of air voids (VV) were selected as the key indexes to determine the PU content $[27,28]$. The TSR and ICL were obtained by the standard freeze-thaw splitting test and the immersion Cantabro loss test according to T0716 and T0733 of JTG E20-2011.

The values of TSR and ICL were specified in reference to the specification of modified asphalt mixtures in JTG F402004. The value range of $K$ was determined according to the specifications of modified asphalt mixtures in the AASHTO specification. The VV is an important volume index of PUM, which not only affects the permeability and durability of PUM but also affects its water stability. The skeleton void structure is finally formed according to the aggregate interlocking theory. The values of VV should guarantee that water can freely discharge after entering the mixture, to avoid water retention within the mixture. Therefore, the key parameters and their values of PUM are presented Table 2 .

Because the recommended mineral gradation eventually formed a skeleton void structure, the binder content determination method of OGFC was used, and the thickness of the PU film was chosen as $14 \mu \mathrm{m} \mathrm{[28].} \mathrm{The} \mathrm{initial} \mathrm{PU} \mathrm{dosage}$ can be determined by the following equation:

$$
A=\frac{2+0.02 a+0.04 b+0.08 c+0.14 d+0.3 e+0.6 f+1.6 g}{48.74},
$$

$P_{b}=h * A$, where $P_{b}$ is the initial PU dosage, $A$ is the total surface area of the aggregates, and $a, b, c, d, e, f$, and $g$ represent the passing percentage for a sieve size of $4.75 \mathrm{~mm}, 2.36 \mathrm{~mm}, 1.18 \mathrm{~mm}$, $0.6 \mathrm{~mm}, 0.3 \mathrm{~mm}, 0.15 \mathrm{~mm}$, and $0.075 \mathrm{~mm}$, respectively.

When the data of Figure 3 were used in equation (1), $A=0.2843$. When $A$ was used in equation (2), $P_{b}=3.98 \%$. The PUM-10 with PU dosages of 3\%, 3.5\%, 4\%, 4.5\%, and 5\% were therefore prepared.

\subsection{Experimental Methods}

2.3.1. Freeze-Thaw Splitting Test. Five groups of Marshall samples were prepared and subjected to $0,1,2,3$, and 4 cycles of freeze-thaw. And, there were five Marshall specimens in every group. Then, the splitting tensile strength of the samples was measured according to T0716-2011 [29], and the freeze-thaw splitting strength ratio (TSR) was calculated.

2.3.2. Immersion Cantabro Loss Test. The ICL of the Marshall specimens was obtained utilizing the Los Angeles abrasion machine following the Chinese specification T0733-2011. The immersion time was varied to compare the water stability of the mixtures comprehensively. The Marshall samples for the immersion Cantabro loss test were placed in the sink at a temperature of $60 \pm 0.5^{\circ} \mathrm{C}$ for 48,72 , 96 , and $120 \mathrm{~h}$ before conducting the immersion Cantabro loss tests. There were three specimens in every group. The ICL was calculated according to the following equation:

$$
\mathrm{ICL}=\frac{m_{0}-m_{1}}{m_{0}} \times 100 .
$$

The weight of the immersion Cantabro loss test specimen was recorded as $m_{0}$, and the maximum residue specimen was obtained, the weight of which was $m_{1}$.

2.3.3. Corelok Test. The PUM was designed by the aggregate interlocking theory and eventually formed a skeleton void structure with a void rate of more than $18 \%$, and the water absorption rate was more than $2 \%$. The Corelok test was used to measure the gross volume relative density of PUM [29]. The vacuum room size was $425 \mathrm{~mm} \times 184 \mathrm{~mm} \times 497 \mathrm{~mm}$ for a vacuum of $101.4 \mathrm{kPa}$ (29.95 in $\mathrm{Hg}$ ). The relative density of the sealed bag used in this experiment was 0.793 . The Corelok device is shown in Figure 5, and the sealed specimens are shown in Figure 6. The Corelok test was conducted according to the steps specified in JTG E20-2011.

2.3.4. Hamburg Wheel Tracking Test. The test was conducted according to T324-2014 of American Association of State Highway and Transportation Officials (AASHTO) [30]. The Hamburg wheel tracking device was from Troxler of America and is shown in Figure 7. The diameter of the cylindrical specimen was $150 \mathrm{~mm}$ and was formed by rotary compaction equipment. There were two specimens in each group. And, the installation of specimens is shown in Figure 8 . The specimens were immersed in $50^{\circ} \mathrm{C}$ water during 


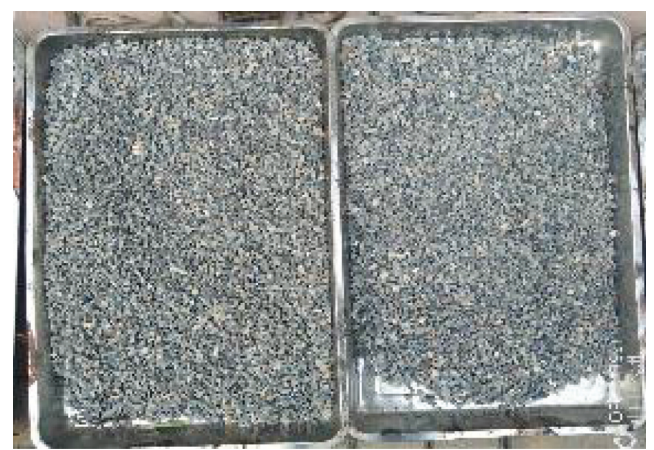

(a)

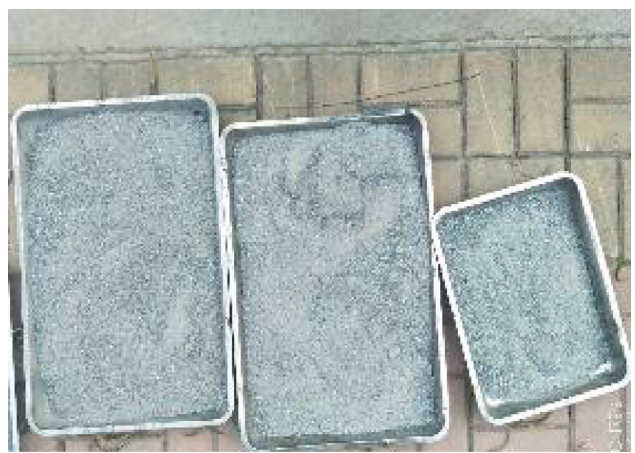

(b)

Figure 2: The basalt and limestone aggregates. (a) 5-10 $\mathrm{mm}$ basalt; (b) 0-3 mm limestone.

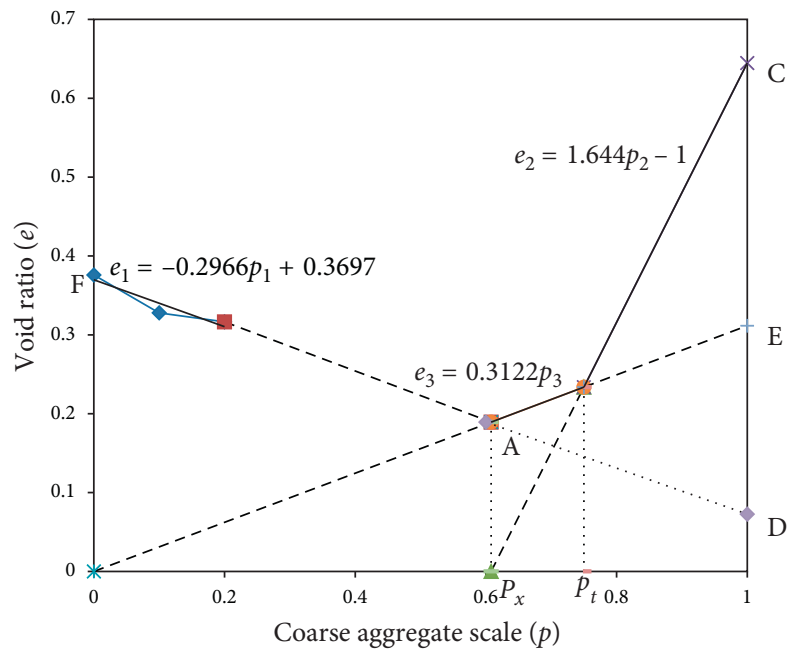

FIgURE 3: The optimum design process of the two aggregates.

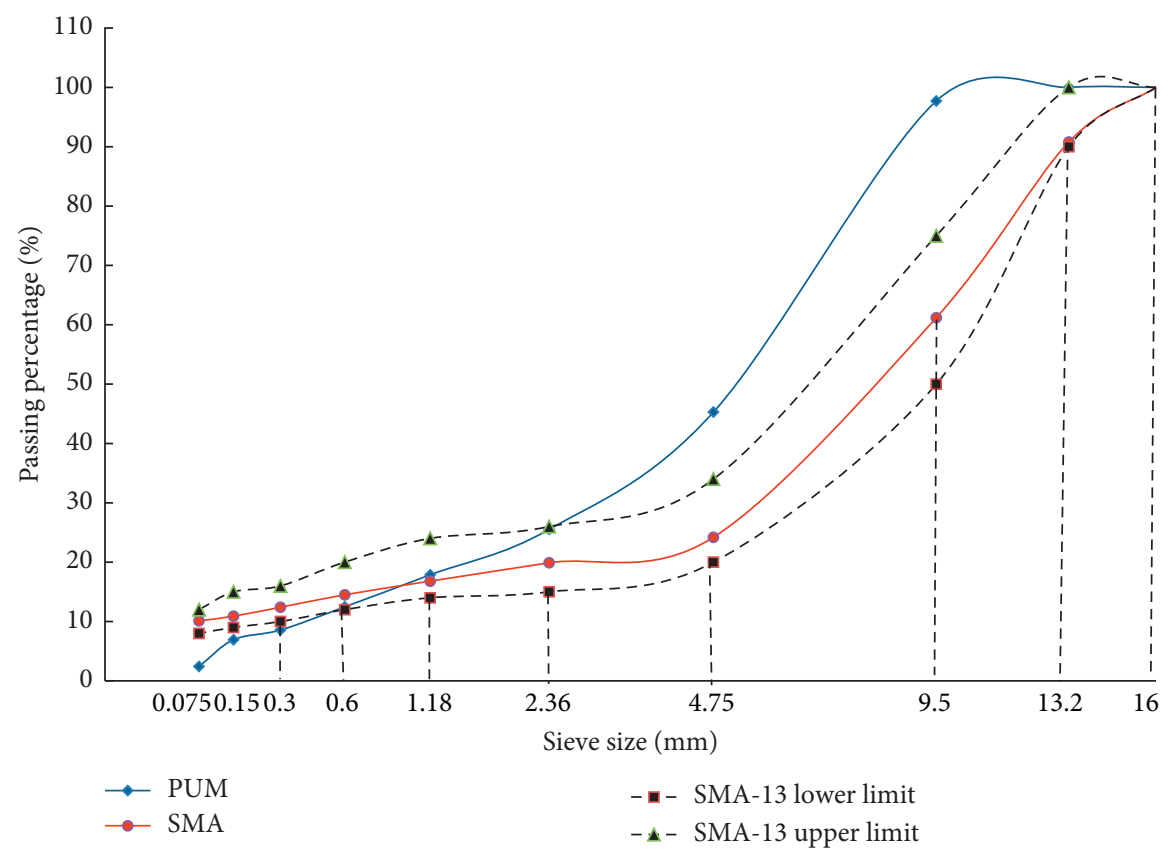

FIGURE 4: Gradations of SMA and PUM. 
TABLE 2: The values of the key index.

\begin{tabular}{lc}
\hline Projects & Value \\
\hline TSR & $\geq 80 \%$ \\
ICL & $\leq 15 \%$ \\
K & $>-0.025$ \\
VV & $18 \% \sim 25 \%$ \\
\hline
\end{tabular}

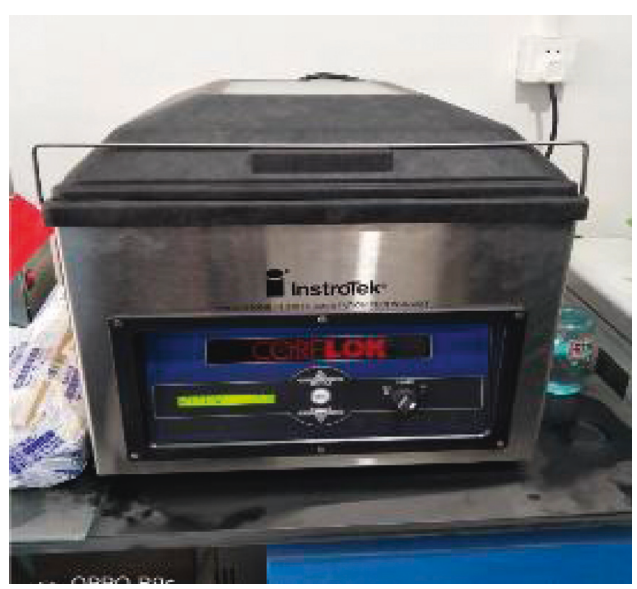

Figure 5: Corelok device.

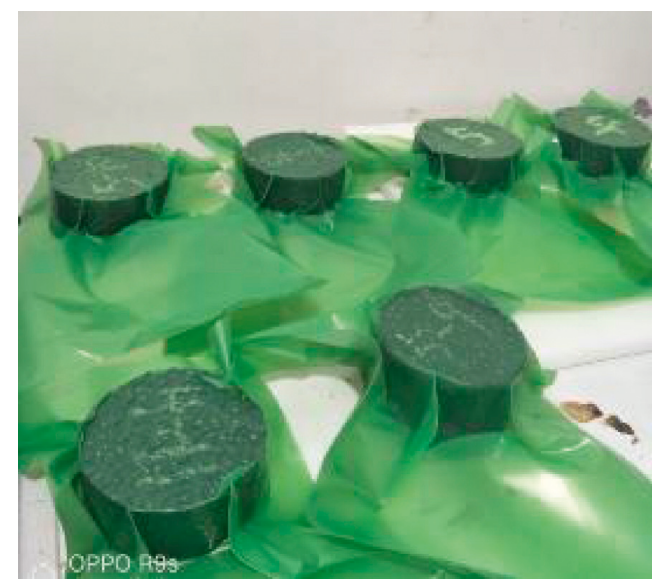

FIGURE 6: Sealed specimens.

the test. The specific conditions of the test are shown in Table 3. The specimens of the two mixtures after the Hamburg wheel tracking test are shown in Figure 9.

2.3.5. Adhesion Test. The adhesion test of 70\# base asphalt and SBS-modified asphalt with aggregates was conducted according to ASTM D3625 and ASTM D1664. Because the strength formation mechanism of PUM was different from the asphalt mixture, the tests for PU are adjusted. The aggregates with the $\mathrm{PU}$ binder were cured at room temperature for $24 \mathrm{~h}$ before testing.

2.3.6. Rutting Test. The rutting resistance tests were conducted at $60^{\circ} \mathrm{C}$ with a fixed wheel pressure of $0.7 \mathrm{MPa}$ in

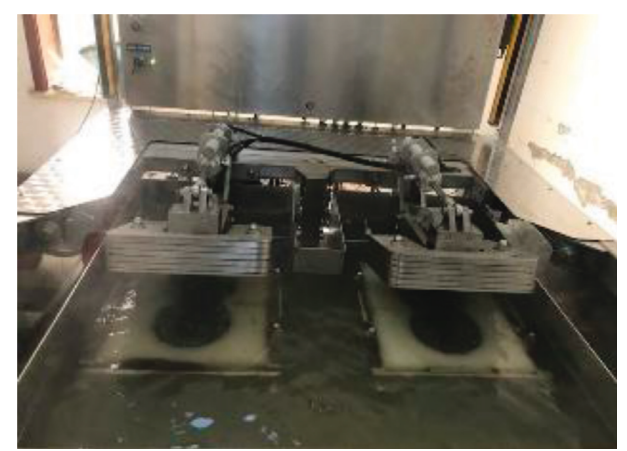

Figure 7: Hamburg wheel tracking device.

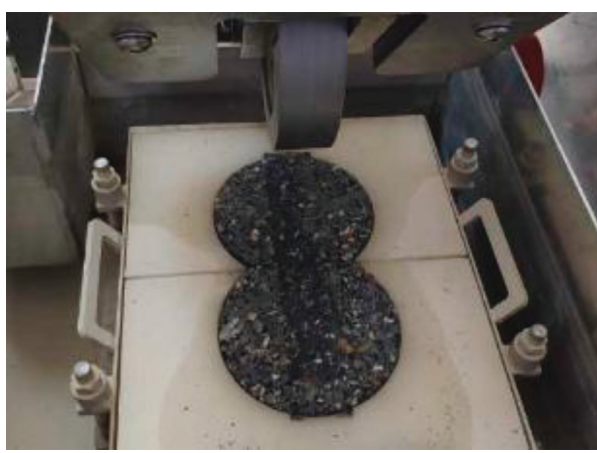

FIGURE 8: Installed specimens.

TABLE 3: Control conditions of the Hamburg wheel tracking test.
Temperature

Load times and rates

Control maximum

deformation

Load mode

\section{$50^{\circ} \mathrm{C}$ \\ 20,000 times, $(52 \pm 2)$ times $/ \mathrm{min}$}

$20 \mathrm{~mm}$

The wheel was with $47 \mathrm{~mm}$ width and $705 \mathrm{~N}$ load accordance with T0733 of JTG E20-2011. The tracking speed of the solid-rub wheel was fixed at 42 cycles/min. Dimensions of the samples were $300 \mathrm{~mm} \times 300 \mathrm{~mm} \times 50 \mathrm{~mm}$, and three samples of each mixture are prepared (JTG E202011).

2.3.7. Low-Temperature Bending Test. The low-temperature bending test was performed in accordance with T0715 of JTG E20-2011. The rolling method was used to form the rutting plate, which was then cut into three test samples of the dimensions $35 \mathrm{~mm} \times 30 \mathrm{~mm} \times 250 \mathrm{~mm}$. The test temperature was $-10^{\circ} \mathrm{C}$, and the loading rate was $50 \mathrm{~mm} / \mathrm{min}$ $[29,31]$.

2.3.8. Dynamic Modulus Test. The specimens were with a diameter of $100 \mathrm{~mm}$ and a height of $150 \mathrm{~mm}$. The test temperatures were $10,20,35$, and $50^{\circ} \mathrm{C}$, and the load frequencies were $0.1,0.2,0.5,1,2,5,10,20$, and $25 \mathrm{~Hz}$. The dynamic modulus was tested according to the regulations of AASHTO T312 [29, 31]. Each group had three samples. The specimen is shown in Figure 10. 


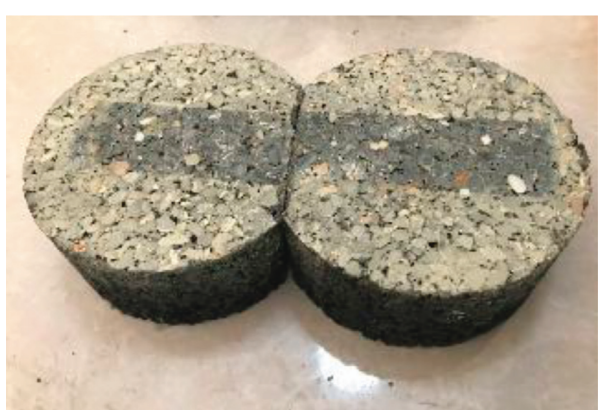

(a)

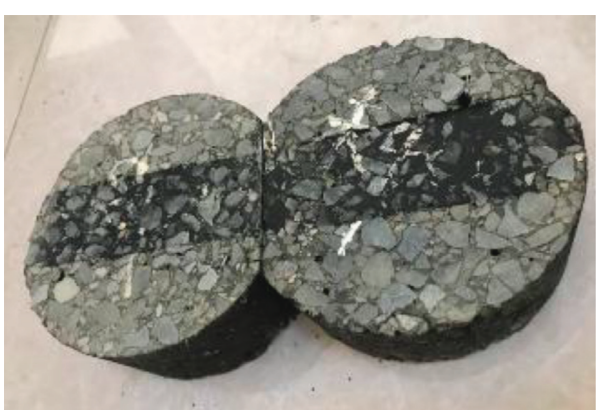

(b)

Figure 9: Specimens after the test. (a) PUM and (b) SMA.

\section{Results and Discussions}

3.1. Determination of the PU Content. In order to determine the optimal PU content, the TSR, ICL, $K$, and VV values of the PUM with the PU content of 3\%, 3.5\%, 4\%, 4.5\%, and 5\% are tested and shown in Figure 11.

Figure 11 shows that the TSR and $K$ value increases whereas ICL decreases when the PU content increases. It indicated a better water stability of the PUM with higher PU contents. However, when the dosage of PU was $5 \%$, the VV of PUM was $16.5 \%$. With this value of VV, the PUM was absorbent but could not completely drain the water, which was incompatible in pavement structures. Therefore, considering that VV was between $18 \%$ and $25 \%$ and the TSR was larger than $80 \%$, the ICL was lower than $20 \%$. The optimal PU content was determined as $4 \%$ based on the four key index values.

The volume of air voids (VV), Marshall stability (MS), bulk specific gravity $\left(G_{\mathrm{mb}}\right)$, and maximum theoretical specific gravity $\left(G_{\mathrm{mm}}\right)$ of the two mixtures are presented in Table 4.

The Marshall stability of the polyurethane mixture was relatively large, which exceeded the range of the Marshall tester. It was due to the high bond strength of the PU binder and the interlocking mixture structure.

\subsection{Performance of the Mixtures}

3.2.1. High-Temperature Stability. The results of the rutting tests are shown in Figure 12. The dynamic stability of the PUM reached 69,997 times/mm, which was about 7.5 times that for SMA and was much larger than the specifications for modified asphalt mixtures in JTG F40-2004 [28].

The high-temperature stability of the PU mixture was determined by the properties of the PU binder and the structure of the mixture. The PU binder had great adhesive strength with the aggregate, and the elastic of PU was obvious. It was difficult to deform under the vehicle load and had a high degree of recovery when the load disappeared [31]. Otherwise, the aggregates with a skeleton interlocking structure had much high strength. Therefore, the dynamic stability of the PU mixture was greater than that of the SBSmodified asphalt mixture. The results implied the hightemperature rutting resistance of PUM was excellent.

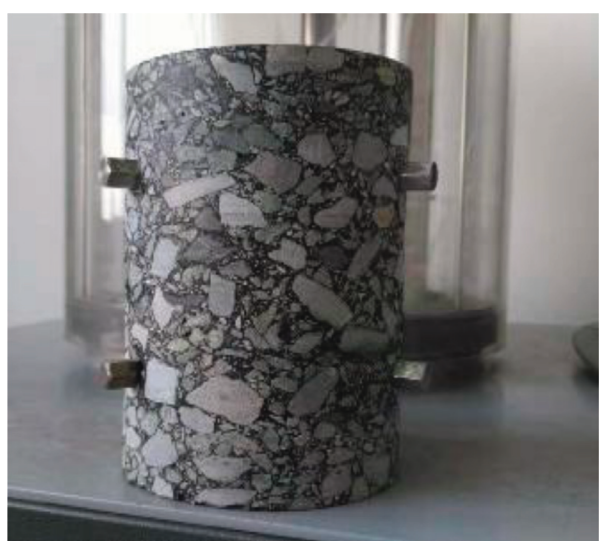

FIGURE 10: SPT test specimen.

3.2.2. Low-Temperature Stability. The results of the lowtemperature bending tests are shown in Figure 13. The bending strain of PUM reached $7045 \mu \varepsilon$, which was about 2.3 times of SMA and was much larger than $3000 \mu \varepsilon$, which was the specified value for modified asphalt mixtures in JTG F402004 [28]. It indicated that PUM had excellent low-temperature stability because of the good low-temperature tenacity of cured PU and the low temperature sensitivity [29]. The low-temperature bending strain of the PUM was relatively large.

The DMA test results of the PU binder showed that the glass vitrification temperature was low, and the PU and PUM were in an elastic state at $-10^{\circ} \mathrm{C}$, so the deformation resistance was relatively strong at this temperature. The PUM was designed on the basis of the aggregate interlocking theory; the aggregates were interlocked with each other, and the PU binder solidified in PUM. An effective network structure was formed. Therefore, the cracking resistance of low temperature was improved.

\subsubsection{Water Stability}

(1) Adhesion Test Results. The adhesion test results are shown in Figures 14 and 15. The adhesion levels of SBS-modified asphalt with two kinds of aggregates were 5, implying excellent adhesion properties for SBS-modified asphalt. The adhesion levels of 70\# base asphalt and limestone were 5 and 


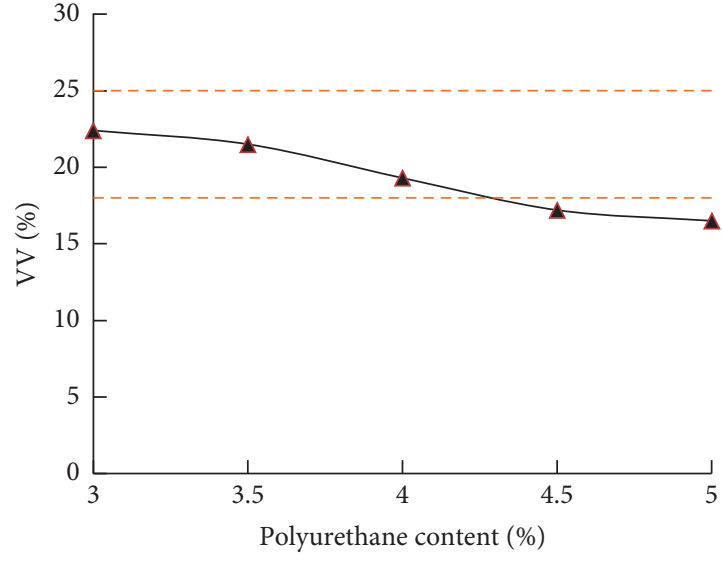

(a)

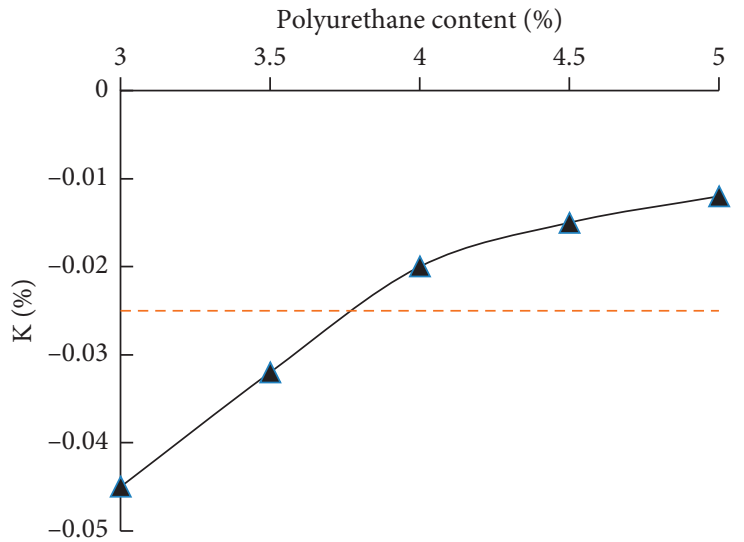

(c)

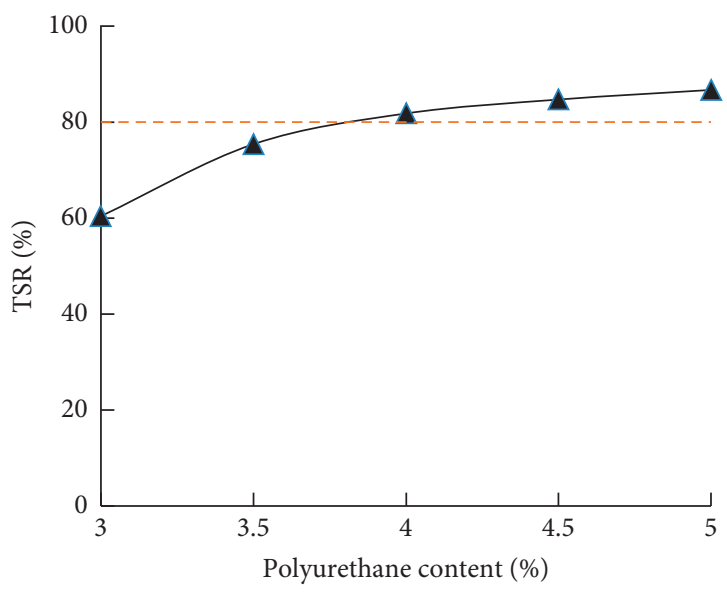

(b)

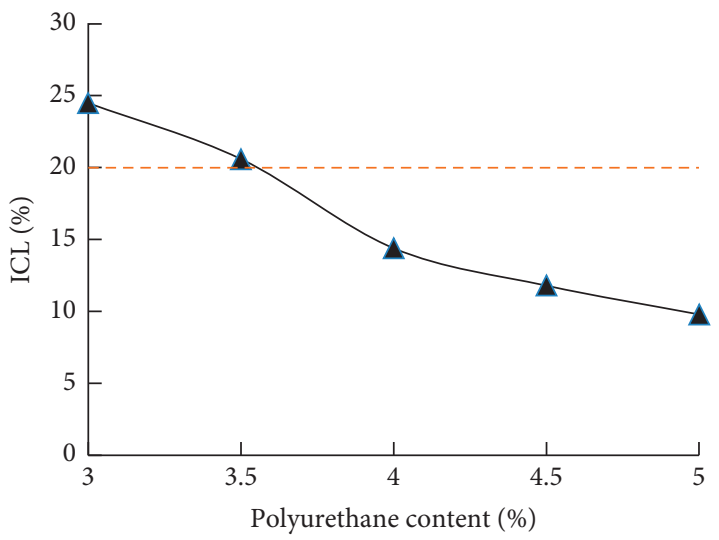

(d)

FIgure 11: Key index value of the PU mixtures with a different PU dosage: (a) VV; (b) TSR; (c) K; (d) ICL.

TABLE 4: The basic properties of the three mixtures.

\begin{tabular}{lccccc}
\hline Mixture types & Binder content $(\%)$ & Volume of air void $(\%)$ & Marshall stability $(\mathrm{kN})$ & $G_{\mathrm{mb}}\left(\mathrm{g} / \mathrm{cm}^{3}\right)$ & $G_{\mathrm{mm}}\left(\mathrm{g} / \mathrm{cm}^{3}\right)$ \\
\hline SMA & 5.8 & 3.8 & 9.89 & 2.571 & 2.673 \\
PUM & 4 & 18.3 & $>50$ & 2.097 & 2.567 \\
\hline
\end{tabular}

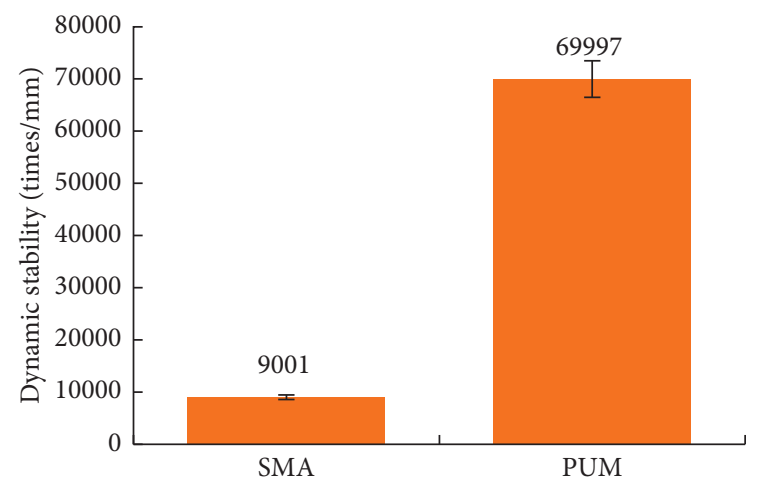

Figure 12: Results of the rutting tests.

5 , and the levels of basalt were 3 and 2, respectively. The adhesion levels of PU and limestone were 4 and 4, indicating that the adhesion of $\mathrm{PU}$ and limestone was better. It

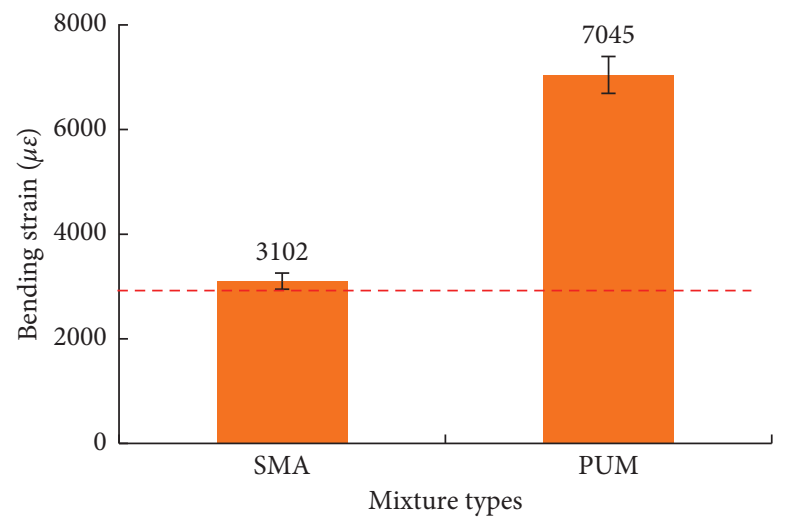

Figure 13: Results of the low-temperature bending tests.

suggested that the adhesion rules between PU and the aggregates were different from those of asphalt. The adhesion level for basalt was higher than for limestone because the $\mathrm{pH}$ 


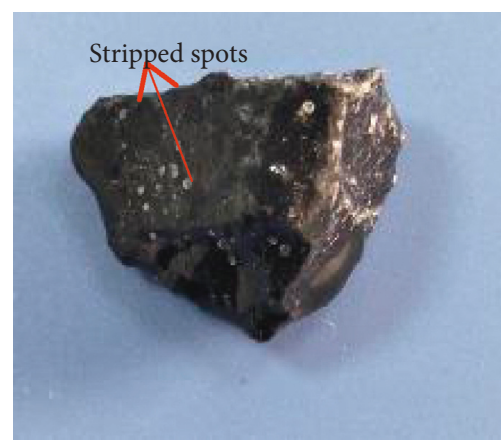

(a)

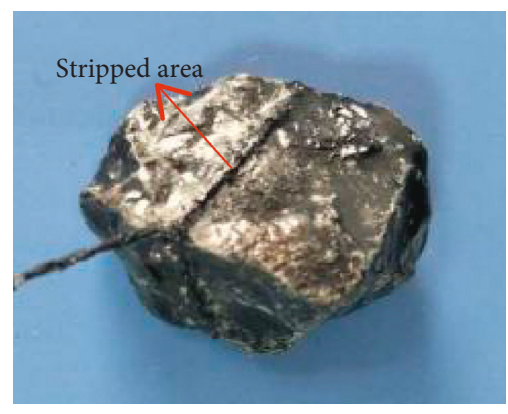

(c)

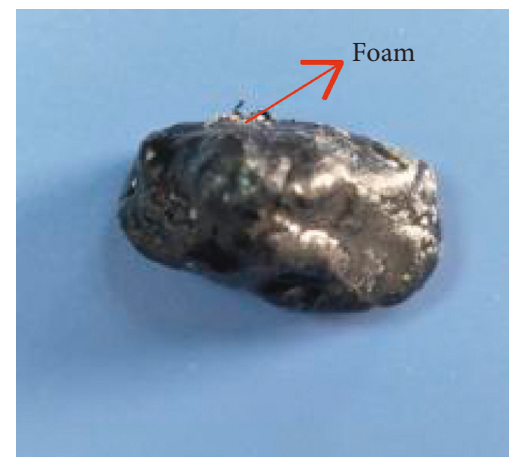

(b)

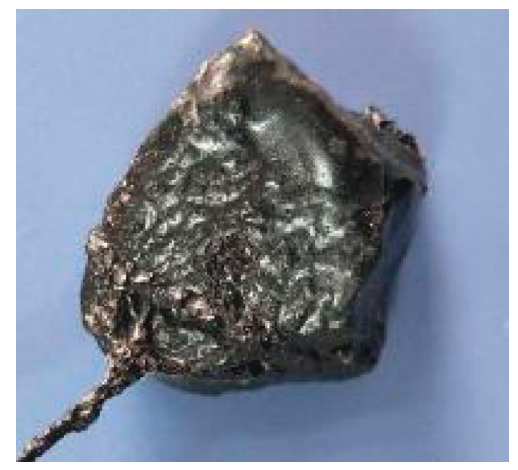

(d)

Figure 14: The adhesion test results of the PU binder: (a) limestone + PU (water immersion); (b) basalt + PU (water immersion); (c) limestone + PU (water boiling); (d) basalt + PU (water boiling).

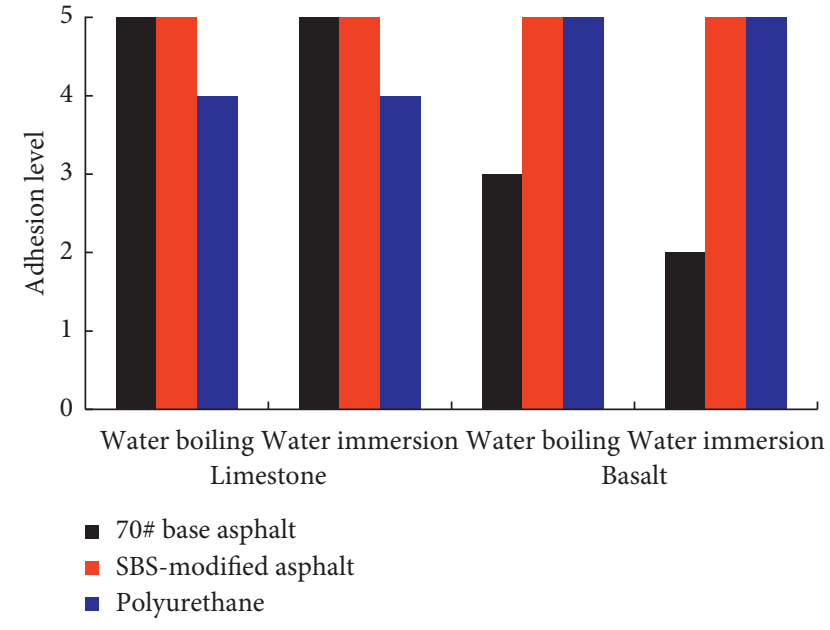

Figure 15: Adhesion level of different aggregates and binders.

value of the PU material was 7-9, and the adhesion with limestone was relatively poor. On the contrary, the adhesion test pictures showed the stripping area between PU and the basalt aggregate was similar with SBS-modified asphalt; however, the stripping area between PU and the limestone was a very thin film. The adhesion level of PU and limestone was relatively lower.

The adhesion level of PU and the basalt aggregate was relatively higher. The results from water boiling and immersion both reach 5 . Therefore, it was proposed to use basalt aggregates to prepare PUM to improve the water stability.

(2) Hamburg Wheel Tracking Test Results. The Hamburg wheel tracking test results of the PUM and SMA mixtures are summarized in Figure 16 and Table 5. The PUM rutting depth curve showed that the stripping inflection point (SIP) of the stripping curve did not appear [33]. The PUM did not strip after 20,000 load cycles, and the rutting depth was very small. It implied that the PUM had excellent water stability. As shown in Figure 16 and Table 3, the maximum rutting depth of the two PUM samples was much smaller than that for the SMA mixture and was about 10\% that of SMA. The PUM had better water stability than SMA. The creep slope of the PUM was lower than that of SMA, indicating that under the combined action of water, temperature, and load. The PUM showed low rut deformation rate and strong resistance to temperature and water interaction. The structure of PUM was relatively stable. This was mainly determined by the good bond strength between the PU binder and the aggregate and the interlocking structure between the aggregates.

(3) Freeze-Thaw Splitting Test Results. As shown in Figure 17, the TSR of PUM and SMA gradually decreased with increasing freeze-thaw cycles. The TSR value of the mixtures after two freeze-thaw cycles was nearly the same as for the standard freeze-thaw cracking test. At this time, the TSR of the two mixtures was greater than $80 \%$, which met the 


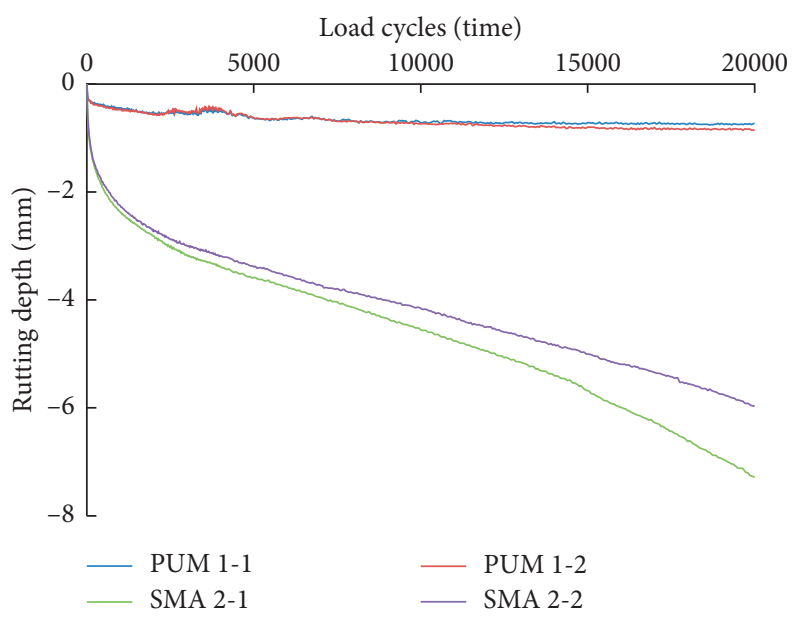

FIGURE 16: Rutting curves for the two mixtures.

TABLE 5: Results of the Hamburg wheel tracking tests.

\begin{tabular}{lcccccc}
\hline Mixture & & VV $(\%)$ & Creep slope $\left(\times 10^{-3}\right)$ & Stripping slope $\left(\times 10^{-3}\right)$ & Rutting depth $(\mathrm{mm})$ & SIP $\left(\times 10^{3}\right)$ \\
\hline \multirow{2}{*}{ PUM } & $1-1$ & 19.75 & -0.02 & - & 0.73 & - \\
& $1-2$ & 19.81 & -0.02 & -0.85 & 7.28 \\
\multirow{2}{*}{ SMA } & $2-1$ & 3.83 & -0.2 & -0.3 & 5.97 \\
& $2-2$ & 3.84 & -0.3 & 15 \\
\hline
\end{tabular}

requirements of JTG F40-2004. The TSR of the SMA mixture was greater than $90 \%$, indicating that its water stability was better at this time. However, when the number of freezethaw cycles increases, the decrease of TSR of SMA was greater than for PUM, suggesting that TSR was relatively stable after repeated freeze-thaw cycles even though it was initially low for the PUM.

(4) Cantabro Loss Test Results. As shown in Figure 18, the ICL index of the two mixtures increased with the immersion time, but the rate for PUM was lower than for SMA. As far as the standard Cantabro loss test was concerned, the ICL of SMA was $13.1 \%$ and the ICL of PUM was $14.4 \%$. However, when the immersion time was longer than $72 \mathrm{~h}$, the ICL of SMA was larger than PUM, indicating that the water stability of PUM was better for prolonged immersion times.

3.3. Dynamic Mechanical Properties. The dynamic modulus of the mixtures is shown in Figure 19. For the same test temperature and loading frequency, the dynamic modulus of the PUM was significantly higher than that of SMA. The dynamic modulus of the two mixtures decreased when the test temperature increased. However, the modulus of SMA declined much faster than for the PUM. Therefore, the modulus difference between PUM and SMA was much larger for higher test temperatures. It indicated that the PUM has excellent dynamic mechanical properties at different temperatures [32]. The temperature stability of PUM was much better. As the load frequency increased, the dynamic modulus of the two mixtures increased as well. However, the increase for SMA was much more significant than PUM. The dynamic modulus of PUM at different

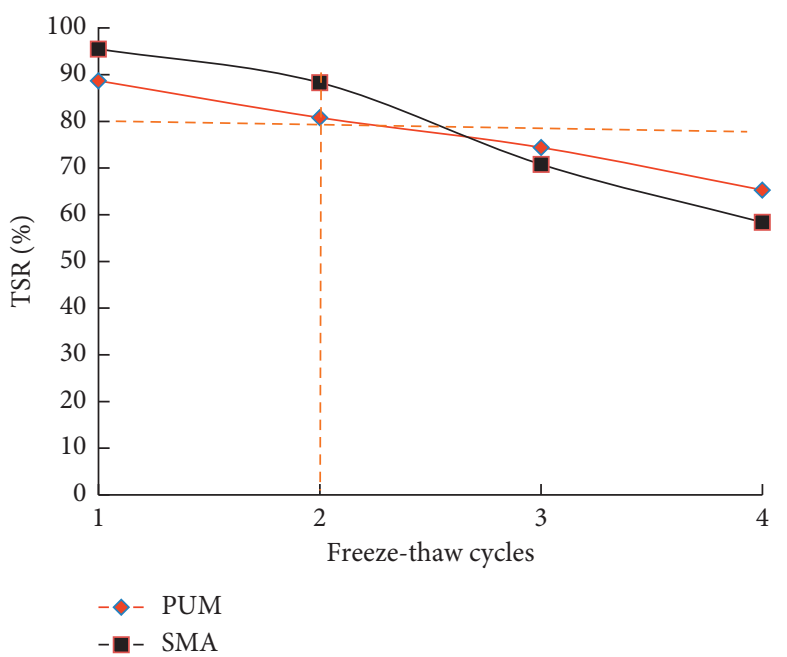

Figure 17: Freeze-thaw test results.

loading frequencies did not change much. The effect of the load frequency on the PUM was relatively small. The PUM was much more stable for different load frequencies.

As shown in Figure 20, the $\varphi$ value of PUM was between $4^{\circ}$ and $6^{\circ}$ and varied within $2^{\circ}$ at different test temperatures and load frequencies. However, $\varphi$ of SMA changed between $15^{\circ}$ and $40^{\circ}$ because the mechanical properties of the PUM were relatively stable and the temperature had less effect on the PUM mixture. The $\varphi$ value for SMA varied greatly with the load frequency and the test temperature, mainly because SBS-modified asphalt was a highly temperature-sensitive material, and the dynamic mechanical properties of SMA at different temperatures varied greatly. Amara et al. have 


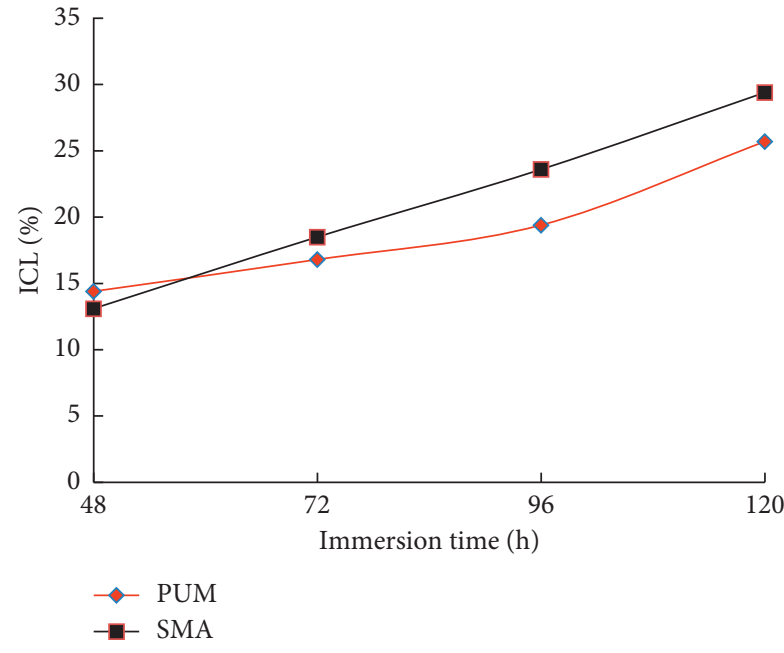

FIgURE 18: Immersion Cantabro loss (ICL) results.

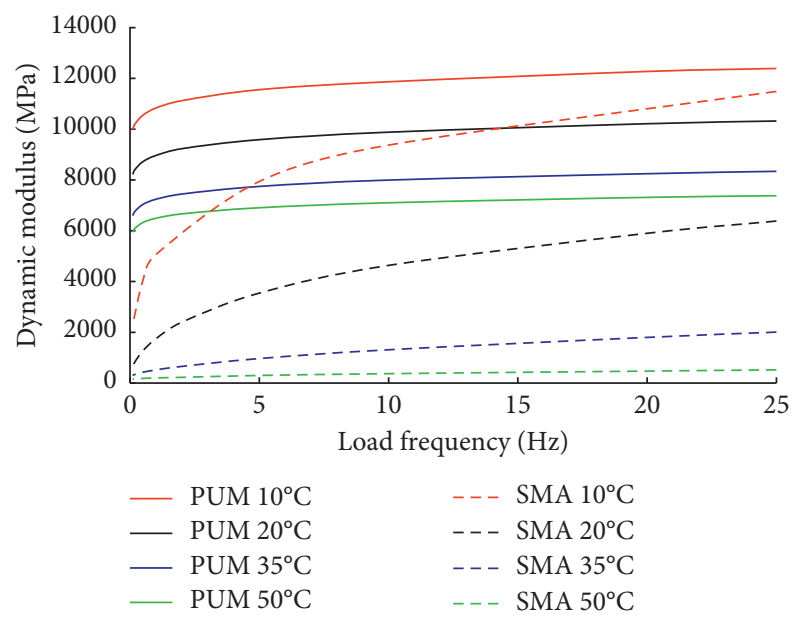

FIgURe 19: Dynamic modulus of the two mixtures.

shown that $\varphi$ described the viscous and elastic property of the material [34]. For viscoelastic materials, $\varphi$ ranged from $0^{\circ}$ to $90^{\circ}$. It was a relative indicator of the elasticity and viscosity coefficient and can reflect the viscoelasticity of a material. As $\varphi$ increases, the viscosity increases. The $\varphi$ value of PUM indicated that it had much obvious elastic property.

3.4. Emission-Reduction and Energy Saving. The aggregates used in this study were treated at the asphalt mixture mixing station first to reduce the moisture and soil at the temperature of $100^{\circ} \mathrm{C}$. When the temperature of the aggregates reached room temperature, PUM was prepared. The fuel consumption during the production of SMA and PUM was calculated, and the energy-saving characteristics of PUM and SMA were compared $[6,35]$. The energy needed was calculated as

$$
Q=\mathrm{cm} \Delta t \text {. }
$$

In the standard state, the complete combustion of $1 \mathrm{~m}^{3}$ of natural gas produces about $43 \mathrm{~mol}$ of $\mathrm{CO}_{2}$ for a weight of

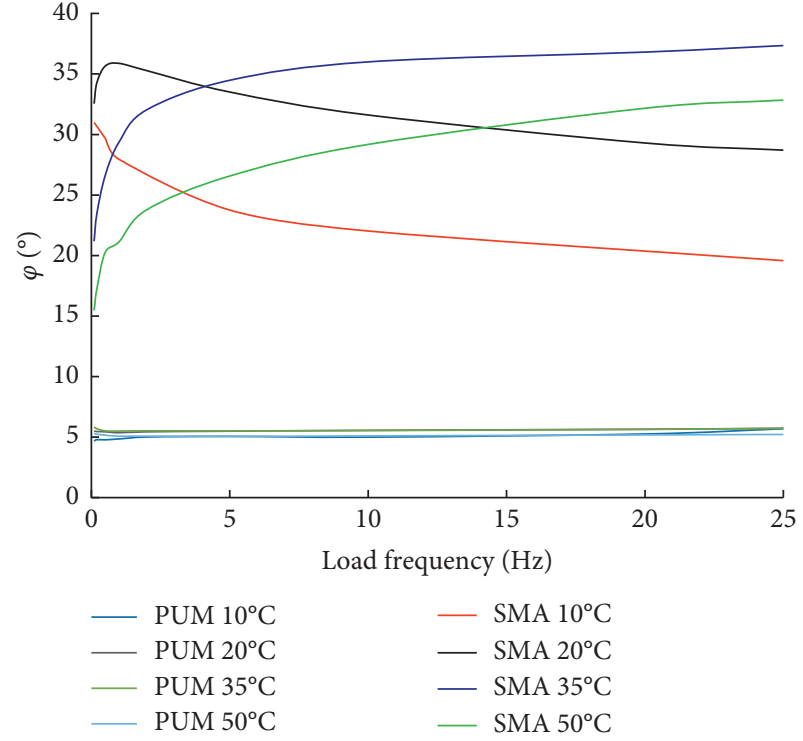

FIgURE 20: $\varphi$ of the two mixtures.

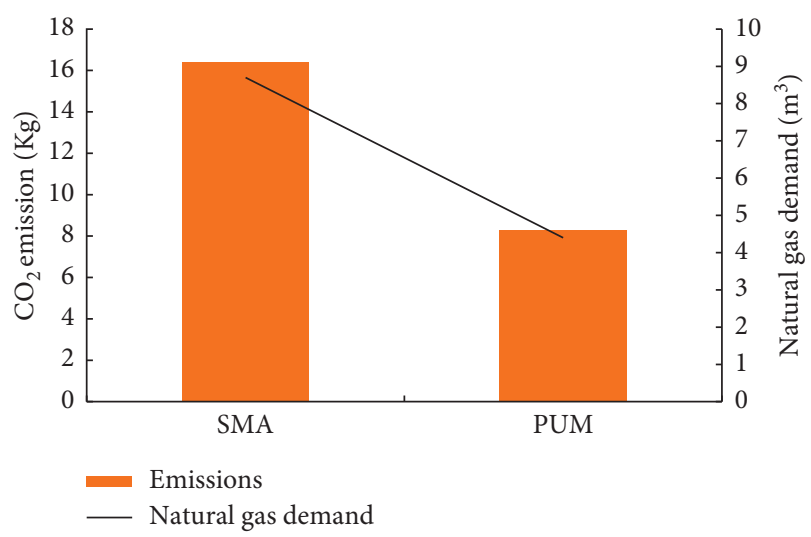

FIgURE 21: Natural gas consumption and $\mathrm{CO}_{2}$ emission per ton mixture.

about $1.885 \mathrm{~kg}$. The $\mathrm{CO}_{2}$ emissions were further calculated by measuring the fuel requirements $[4,36]$. The natural gas needed and $\mathrm{CO}_{2}$ emissions for the mixtures are summarized in Figure 21.

The natural gas needed and the $\mathrm{CO}_{2}$ emission for PUM were about $50.9 \%$ those for SMA, and around $4.26 \mathrm{~m}^{3}$ of natural gas was saved per ton PUM. It was estimated that the annual consumption of the asphalt mixture in China is about 3 billion tons [3]. If PUM was used, it would save about 12.8 billion $\mathrm{m}^{3}$ of natural gas, and the $\mathrm{CO}_{2}$ emission would be reduced by 24 million tons. This was very significant for nonrenewable gas resources. The PU binder was a single-component wet curing material and did not need to be heated. Therefore, no smoke was discharged during the production, and the emission of toxic and harmful gases was eliminated [4, 37].

The PUM displayed good performance and can improve construction conditions and protect environment; it can be used in pavement engineering and may play a significant role in solving global warming problems. 


\section{Conclusions}

This study compared the properties of cold-mixed PUM with hot-mixed SMA through a series of laboratory tests. The cold-mixed PUM showed excellent properties, and the following conclusions could be drawn:

(1) The optimal PU content was $4 \%$ as far as water stability indexes were concerned.

(2) The dynamic stability and the bending strain of PUM were 7.5 and 2.3 times that for SMA, respectively. The PUM has excellent high- and low-temperature stability.

(3) The adhesion level of PU and basalt was relatively higher than for limestone. An SIP did not appear in the HWTD rutting curve of the PUM. The PUM had excellent water-temperature stability. The improved freeze-thaw splitting test and the immersion Cantabro loss test indicated a better long-term water stability of PUM.

(4) The dynamic modulus of PUM was higher and the $\varphi$ value was less than SMA. The two indexes for PUM were much more stable under different test temperatures and load frequencies.

(5) The energy consumption and $\mathrm{CO}_{2}$ emission of PUM were about $50.9 \%$ of SMA. The cold-mixed PUM was an energy-saving and emission-reducing material.

\section{Data Availability}

The data used to support the findings of this study are included in Supplementary Materials.

\section{Conflicts of Interest}

The authors declare that they have no conflicts of interest.

\section{Acknowledgments}

This research was sponsored by the Fundamental Research Funds for the Central Universities (grant no. 310821163502), the Transportation Department of Shandong Province (grant no. Lujiaokeji (2017) 28), the Xixian New District Management Committee of Shaanxi Province (grant no. 2017 44), the Science and Technology Bureau of Pingdingshan of China (grant no. 2018610002000604), and the Scientific Research Project for the Education Department of the Shaanxi Provincial Government (grant no. 18JK0079).

\section{Supplementary Materials}

The file with the name of " 6.10 data" was the origin data of the curves in the manuscript. The file with the name of "HWTD" was the results of the Hamburg wheel tracking test. The file with the name of "dynamic modulus data" was the results of dynamic modulus tests with different temperatures and frequencies. (Supplementary Materials)

\section{References}

[1] T. Wang, F. Xiao, X. Zhu, B. Huang, J. Wang, and S. Amirkhanian, "Energy consumption and environmental impact of rubberized asphalt pavement," Journal of Cleaner Production, vol. 180, pp. 139-158, 2018.

[2] ISO 14044, ISO 14044: 2006 Environmental Management-Life Cycle Assessment-Requirements and Guidelines, International Organization for Standardization, Geneva, Switzerland, 2006.

[3] Q. Zhu and Y. Geng, "Drivers and barriers of extended supply chain practices for energy saving and emission reduction among Chinese manufacturers," Journal of Cleaner Production, vol. 40, no. 2, pp. 6-12, 2013.

[4] F. Gao, Study on the Quantitative Analysis of Energy Consumption and Emissions during the Period of Asphalt Pavement Construction Based on LCA, Chongqing Jiaotong University, Chongqing, China, 2016.

[5] I. Bartolozzi, I. Antunes, and F. Rizzi, "The environmental impact assessment of asphalt rubber: life cycle assessment," in Proceedings of the 5th Asphalt Rubber Roads of the Future International Conference, pp. 799-819, Munich, Germany, October 2012.

[6] K. Park, Y. Hwang, S. Seo, and H. Seo, "Quantitative assessment of environmental impacts on life cycle of highways," Journal of Construction Engineering and Management, vol. 129, no. 1, pp. 25-31, 2003.

[7] A. Almeida-Costa and A. Benta, "Economic and environmental impact study of warm mix asphalt compared to hot mix asphalt," Journal of Cleaner Production, vol. 112, pp. 2308-2317, 2016.

[8] GB 16780-2007, The Norm of Energy Consumption per Unit Products of Cement, General Adiministration of Quality Supervision, Inspection and Quarantine of the People's Republic of China, Beijing, China, 2007.

[9] IPCC, 2006 IPCC Guidelines for National Greenhouse Gas Inventories, Intergovernmental Panel on Climate Change, Geneva, Switzerland, 2006.

[10] Q. Wang, S. Chen, T. Wang, and X. Zhang, "Damping, thermal, and mechanical properties of polyurethane based on poly(tetramethylene glycol)/epoxy interpenetrating polymer networks: effects of composition and isocyanate index," Applied Physics A, vol. 104, no. 1, pp. 375-382, 2011.

[11] R. Li, H. Wang, and G. Zhou, "Experimental study on the strength and influencing factors of multi-pore polyurethane gravel mixture," Chinese and Foreign Road, vol. 35, no. 1, pp. 244-247, 2015.

[12] H. Wang, R. Li, X. Wang et al., "Strength and road performance for porous polyurethane mixture," China Journal of Highway and Transport, vol. 27, no. 10, pp. 24-31, 2014.

[13] L. Cong, T. Wang, L. Tan, J. Yuan, and J. Shi, "Laboratory evaluation on performance of porous polyurethane mixtures and OGFC," Construction and Building Materials, vol. 169, pp. 436-442, 2018.

[14] J. Chen, X. Yin, H. Wang, and Y. Ding, "Evaluation of durability and functional performance of porous polyurethane mixture in porous pavement," Journal of Cleaner Production, vol. 188, pp. 12-19, 2018.

[15] S. Sun, Applied Study on Eliminating Snow by Self-Stress of Polyurethane Rubber Particles Mixture, Hebei University of Technology, Tianjin, China, 2013.

[16] M. Sun, Research on Performance of Polyurethane Porous Elastic Pavement Mixture, Southeast University, Nanjing, China, 2016.

[17] J. Chen, C. Yao, H. Wang, W. Huang, X. Ma, and J. Qian, "Interface shear performance between porous polyurethane 
mixture and asphalt sublayer," Applied Sciences, vol. 8, no. 4, p. 623, 2018.

[18] D. Wang, P. Liu, Z. Leng et al., "Suitability of poroelastic road surface (PERS) for urban roads in cold regions: mechanical and functional performance assessment," Journal of Cleaner Production, vol. 165, pp. 1340-1350, 2017.

[19] D. Wang, A. Schacht, Z. Leng, C. Leng, J. Kollmann, and M. Oeser, "Effects of material composition on mechanical and acoustic performance of poroelastic road surface (PERS)," Construction and Building Materials, vol. 135, pp. 352-360, 2017.

[20] G. Lu, L. Renken, T. Li, D. Wang, H. Li, and M. Oeser, "Experimental study on the polyurethane-bound pervious mixtures in the application of permeable pavement," Construction and Building Materials, vol. 202, pp. 838-850, 2019.

[21] T. Törzs, G. Lu, A. O. Monteiro, D. Wang, J. Grabe, and M. Oeser, "Hydraulic properties of polyurethane-bound permeable pavement materials considering unsaturated flow," Construction and Building Materials, vol. 212, pp. 422-430, 2019.

[22] G. Lu, P. Liu, Y. Wang, S. Faßbender, D. Wang, and M. Oeser, "Development of a sustainable pervious pavement material using recycled ceramic aggregate and bio-based polyurethane binder," Journal of Cleaner Production, vol. 220, pp. 10521060, 2019.

[23] P. L. Xu and S. Q. Zhang, Handbook of Polyurethane Materials, Chemical Industry Press, Beijing, China, 2011.

[24] F. Olard and D. Perraton, "On the optimization of the aggregate packing characteristics for the design of high-performance asphalt concretes," Road Materials and Pavement Design, vol. 11, no. sup1, pp. 145-169, 2010.

[25] F. Olard, "GB5 mix design: high-performance and cost-effective asphalt concretes by use of gap-graded curves and SBS modified bitumen," Road Materials and Pavement Design, vol. 13, no. sup1, pp. 234-259, 2012.

[26] L. Xu, Y. Bi, and D. Yu, "Gradation optimized design and performance analysis of skeleton dense asphalt mixture," Journal of Shandong Construction University, vol. 32, no. 3, pp. 263-268, 2017, in Chinese.

[27] Ministry of Transport of the People's Republic of China, Technical Specifications for Construction of Highway Asphalt Pavements (JTG F40-2004) by the Ministry of Transport of the People's Republic of China, China Communication Press, Beijing, China, 2004.

[28] Ministry of Transport of the People's Republic of China, Standard Test Methods of Bitumen and Bituminous Mixtures for Highway Engineering (JTG E20-2011) by the Ministry of Transport of the People's Republic of China, China Communication Press, Beijing, China, 2011.

[29] AASHTO T324-2014, Hamburg Wheel-Track Testing of Compacted Hot-Mix Asphlt (HMA), American Association of State Highway and Transportation Officials, Washington, DC, USA, 2014.

[30] M. Sun, M. Zheng, G. Qu, K. Yuan, Y. Bi, and J. Wang, "Performance of polyurethane modified asphalt and its mixtures," Construction and Building Materials, vol. 191, pp. 386-397, 2018.

[31] Y. Zhang, Development and Performance Research of Porous Colored Cold-Mix Epoxy Asphalt Mixture Pavement for Long Tunnels, Chongqing Jiaotong University, Chongqing, China, 2017.

[32] L. Qi, A. Sha, and K. Chen, "Research on the water stability of asphalt mixture based on the HWTD," Journal of Wuhan University of Technology, vol. 31, no. 8, p. 42, 2009, in Chinese.
[33] V.S. Punith and A. Veeraragavan, "Characterization of OGFC mixtures containing reclaimed polyethylene fibers," Journal of Materials in Civil Engineering, vol. 23, no. 3, pp. 335-341, 2010.

[34] L. Amara, "Comparison between resilient modulus and dynamic modulus of hot-mix asphalt as material properties for flexible pavement design," in Proceedings of the 84th Transportation Research Board Annual Meeting, Washington DC, USA, January 2005.

[35] Z. Zhang, Y. Luo, and K. Zhang, "Review on Hamburg wheeltrack device evaluation of asphalt mixture," Materials Introduction, vol. 31, no. 3, pp. 96-105, 2017, in Chinese.

[36] J. Wei, S. Cui, and J. Hu, "Research on dynamic modulus of asphalt mixtures," Journal of Building Materials, vol. 11, no. 6, pp. 657-661, 2008, in Chinese.

[37] J. Wang, J. Yuan, F. Xiao, Z. Li, J. Wang, and Z. Xu, "Performance investigation and sustainability evaluation of multiple-polymer asphalt mixtures in airfield pavement," Journal of Cleaner Production, vol. 189, pp. 67-77, 2018. 


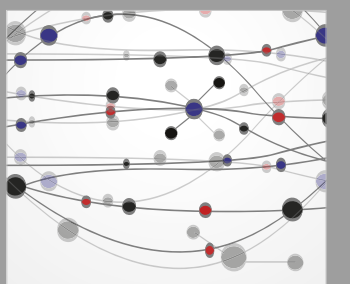

The Scientific World Journal
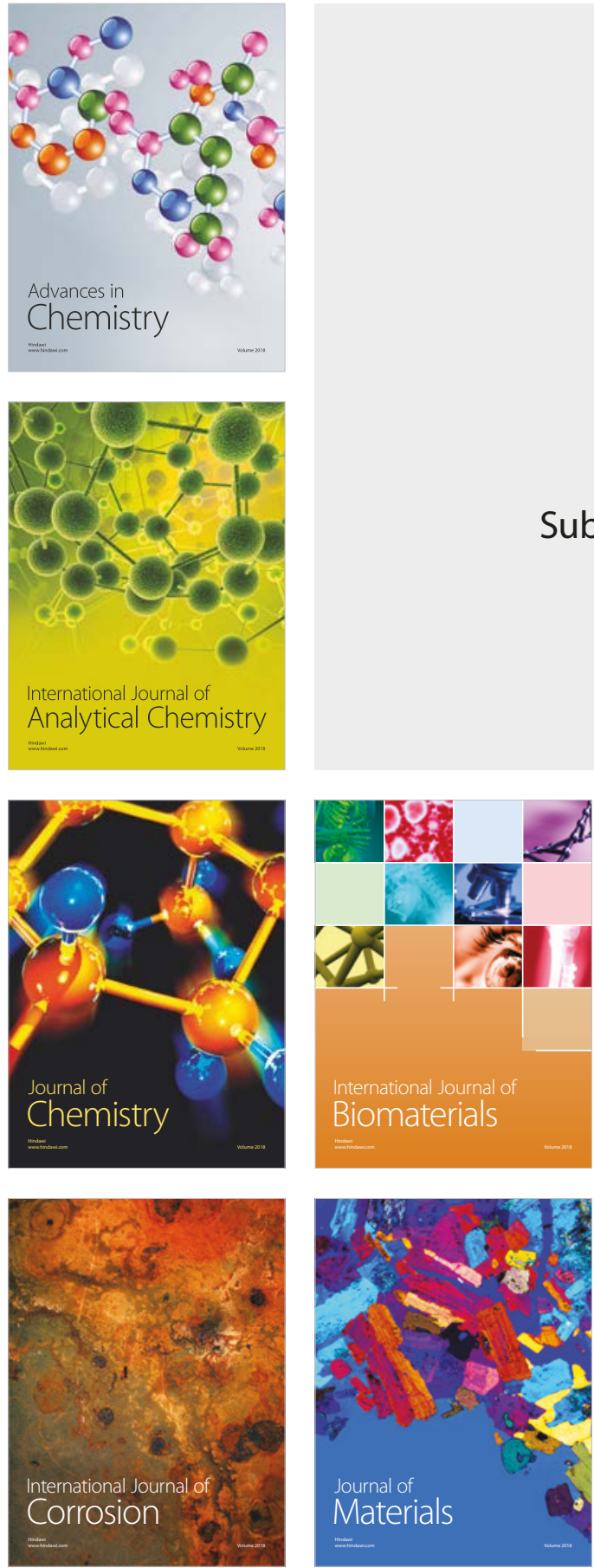

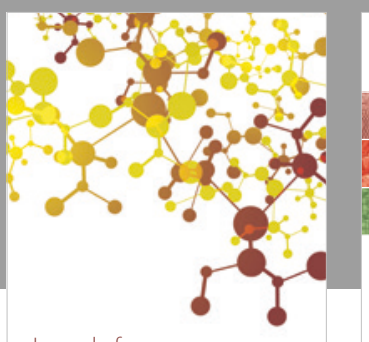

Journal of

Applied Chemistry
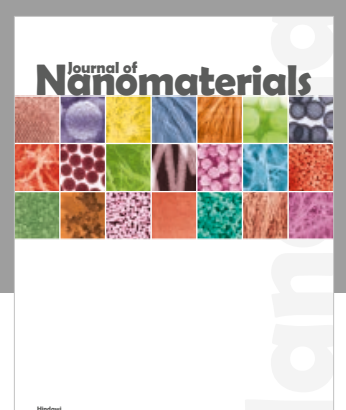

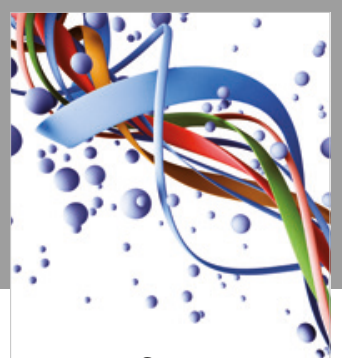

Scientifica

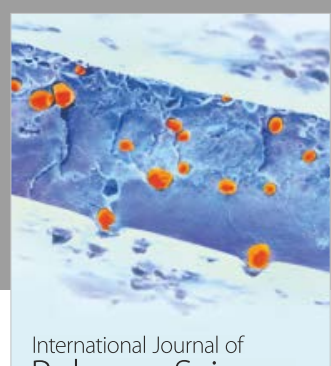

Polymer Science

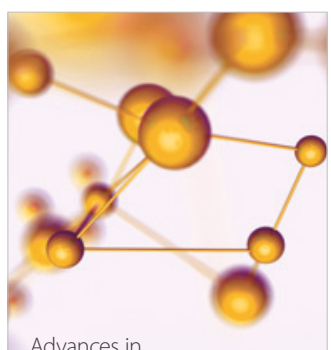

Physical Chemistry
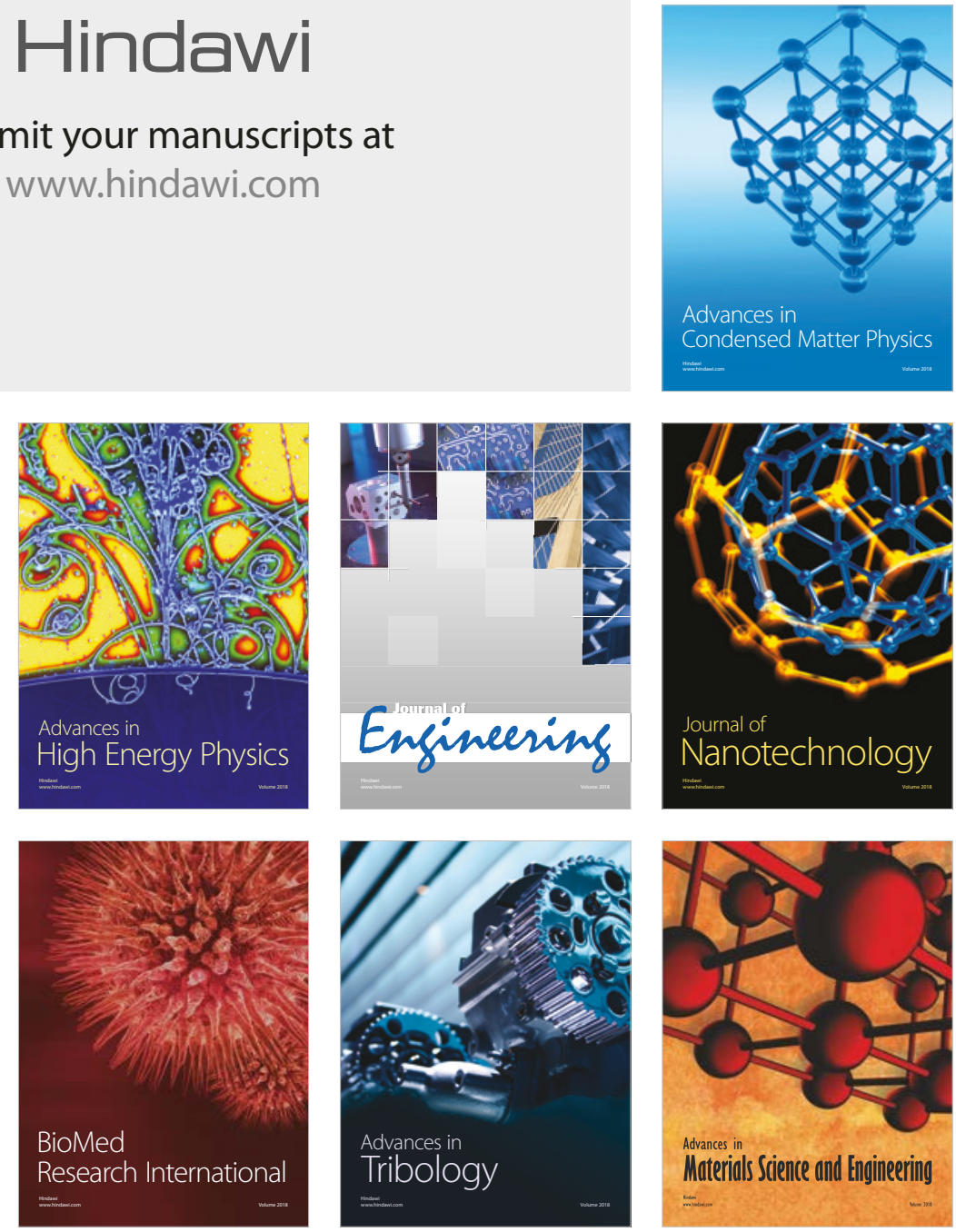